Tiempos antiperonistas en la Patagonia argentina.

La acción de las Comisiones Investigadoras durante la

"Revolución Libertadora"

Martha Ruffini

páginas / año 8 - n 16 / ISSN 1851-992X / pp. 61-81 / 2016

http://revistapaginas.unr.edu.ar/index.php/RevPaginas

\title{
Tiempos antiperonistas en la Patagonia argentina. La acción de las Comisiones Investigadoras durante la "Revolución Libertadora"
}

\author{
Antiperonist times in Patagonia Argentina. The action of the Investigating \\ Committees during the "Liberating Revolution"
}

\author{
Martha Ruffini \\ Centro de Estudios de la Argentina Rural (Universidad Nacional de Quilmes) \\ Consejo Nacional de Investigaciones Científicas y Técnicas, Argentina \\ meruffini@gmail.com
}

\section{Resumen}

En 1955 se produjo un nuevo quiebre institucional en Argentina, que provocó el final del llamado "peronismo histórico" (1946-1955). A partir de entonces, la autodenominada Revolución Libertadora (1955-1958) quedó asociada indisolublemente a la exclusión política mediante la proscripción electoral del partido justicialista, sus ex funcionarios y el líder mismo. En la Patagonia la Dictadura Militar puso entre paréntesis la creación de nuevas provincias dispuesta por el peronismo. Al igual que en el resto de las provincias, el gobierno de facto ordenó la adopción de medidas tendientes a perseguir, investigar y juzgar las actividades del partido peronista y de sus principales funcionarios en el marco del proceso de desperonización impulsado desde el gobierno de facto. En ese sentido la acción de las comisiones y sub comisiones Investigadoras provinciales se materializó en una multiplicidad de denuncias, detenciones y cesantías que demuestran la trama del poder anudada en los ex territorios nacionales del sur, con una sociedad movilizada que colaboró activamente con la intervención federal como parte del aval al pacto proscriptivo, evidenciando la escasa valencia del concepto democracia como rasgo dominante.

\section{Palabras claves}

Dictadura, Exclusión, Patagonia, Peronismo, Proscripción

\begin{abstract}
In 1955 there was a new institutional breakdown in Argentina that caused the end of the "historical Peronism" (1946-1955). Since then, the self-appointed Liberating Revolution (1955-1958) remained indissolubly associated to the political exclusion by the electoral proscription of the Peronist party, its former officials and the leader himself. In Patagonia the Military Dictatorship bracketed the creation of new provinces disposed by Peronism. Just like in the other provinces the illegally government ordered the adoption of measures to pursue, investigate and prosecute the activities of the Peronist party and its principal officials under the "desperonización" process promoted by the illegal government. In this sense the action of committees and sub provincial commissions of inquiry materialized in a multitude of complaints, arrests and dismissals that show the plot of power in the former national tied southern territories, with a mobilized society that actively collaborated with
\end{abstract}




\section{Tiempos antiperonistas en la Patagonia argentina}

the federal intervention as part of the endorsement of the pact proscriptive, evidencing the low valence of democracy as a dominant trait concept.

\section{Keywords}

Dictatorship, Exclusion, Patagonia, Peronism, Proscription

\section{Introducción}

En 1955 el golpe de Estado que derrocó al presidente Juan Domingo Perón (19461955) abrió una etapa histórica en la que la exclusión política emergió como nota dominante. El gobierno militar instalado bajo el liderazgo de los generales Eduardo Lonardi, Pedro Eugenio Aramburu y el Contralmirante Isaac Rojas provocó un quiebre profundo que fue más allá del desplazamiento del gobernante elegido democráticamente. A partir de ese momento se profundizó la polarización peronismo/antiperonismo, fragmentación exacerbada por las medidas tomadas por el gobierno de facto, la autodenominada "Revolución Libertadora" (1955-1958), que pronto devino en Dictadura.

Para el sur del país -la Patagonia- el golpe implicó un paréntesis hacia la autonomía política. Durante el peronismo, los territorios nacionales de Chaco, La Pampa (1951) y Misiones (1953) fueron convertidos en nuevas provincias. Pero en Formosa y las provincias patagónicas -Neuquén, Río Negro, Chubut, Santa Cruz- la provincialización se produjo en el último año del gobierno peronista mediante la sanción de la ley № 14.408. Con el golpe militar, postergar la instalación de las nuevas provincias fue una decisión basada en la necesidad de realizar una tarea previa de "depuración ideológica” y eliminación de los "resabios peronistas".

Entre 1955 y 1958 el gobierno militar mantuvo la proscripción electoral del partido y de su líder, pero intentó borrar al peronismo de la historia argentina mediante un proceso de desperonización compulsiva. En ese marco y con la complicidad de sus aliados civiles -partidos políticos, corporaciones y el clero- decidió iniciar una investigación profunda de las actividades del peronismo, de sus principales dirigentes y del desempeño de los organismos estatales. Para justificar esta "cruzada pedagógica", ordenó una amplia investigación. Con ese objetivo, fue creada una Comisión Nacional de Investigaciones y se dispuso replicar este formato en todo el país.

La acción desarrollada por estas comisiones nos muestra una radiografía de la política y la sociedad en la que la antinomia amigo-enemigo traducida en la disputa peronismo y antiperonismo se mostraba en su faz más aguda. Y en el caso de la Patagonia, con Estados en formación, la acción desarrollada por las comisiones provinciales y sub-comisiones traduce los consensos, orientaciones y definiciones con los que las provincias iniciaban su historia institucional. En ese sentido, creemos que la modalidad político-partidaria de las nuevas provincias del sur y la discusión acerca de las díadas antinómicas democracia/autoritarismo y peronismo/antiperonismo en las dirigencias políticas provinciales estuvo moldeada e influida por el momento de la "Revolución Libertadora", fundamentalmente en lo 


\section{Martha Ruffini}

atinente a la definición de su perfil provincial y la relación que se establecerá entre los poderes del nuevo Estado. El rol activo de la dirigencia partidaria y de gran parte de la sociedad civil en la trama de las investigaciones augura expectativas poco favorables para el ejercicio del disenso y el pluralismo político en los futuros gobiernos constitucionales patagónicos.

En cuanto a las comisiones investigadoras, María Estela Spinelli (2005) las considera parte del proyecto pedagógico de la desperonización ya que la difusión de los resultados de las investigaciones estigmatizaba al peronismo y alentaba la desmitificación del líder y de su gobierno. Más recientemente, Silvana Ferreyra (2014) ha trabajado las comisiones investigadoras en la provincia de Buenos Aires y Chaco en pos de articular la tipificación de delitos, las motivaciones de las denuncias y su relación con los conflictos políticos. En cuanto a la Patagonia, existen pocas referencias acerca del alcance de la desperonización y la persecución política y sobre la acción de las comisiones investigadoras provinciales o locales. Para Neuquén, un primer acercamiento en este sentido se advierte en Mases y Cuminao, y en Rafart y Mases; mientras que para Santa Cruz en Bona y Vilaboa. Las investigaciones sobre Río Negro ponen el acento en el gobierno del Gral. Aramburu como el momento de mayor violencia política en el que rápidamente se puso en marcha el aparato represivo, se activaron las comisiones investigadoras y se detuvieron a las autoridades del gobierno justicialista. Por nuestra parte, hemos comprobado que en la provincia de Río Negro la represión estatal estuvo presente en ambos gobiernos -Lonardi y Aramburu-, señalándose la participación activa de la sociedad civil y política rionegrina en la labor de las comisiones investigadoras (Ruffini, 2012). ${ }^{1}$

\section{Entre la palabra y la acción: la "Revolución Libertadora” y el discurso del orden y la reparación}

El consenso para provocar la caída del gobierno peronista tenía una larga gestación. Durante su mandato, Perón se había enfrentado con las grandes corporaciones

\footnotetext{
${ }^{1}$ María Estela Spinelli. Los vencedores vencidos. El antiperonismo y la revolución libertadora. Buenos Aires, Biblos, 2005; Silvana Ferreyra. "El delito de ser peronista. Una aproximación a las Comisiones Investigadoras durante la Revolución Libertadora", ponencia presentada en IV Congreso de Estudios sobre Peronismo, San Miguel de Tucumán, Tucumán, 2014; Enrique Mases y Mariano López Cuminao. "La luz de un fosforo fue. Auge y decadencia de la Unión Cívica Radical Intransigente Neuquina 19571962", en Francisco Camino Vela, (compilador), El mundo de la política en la Patagonia Norte. Neuquén, Editorial de la Universidad del Comahue EDUCO, 2012; Gabriel Rafart y Enrique Mases. El peronismo desde los territorios a la Nación. Su historia en Neuquén y Río Negro 1943-1958.Neuquén, Editorial de la Universidad del Comahue EDUCO, 2001; Aixa Bona y Juan Vilaboa. "La transición política de los territorios nacionales y la caída del peronismo. El caso de Santa Cruz", ponencia presentada en III Jornadas de Historia de la Patagonia, San Carlos de Bariloche, Río Negro, 2008; Aixa Bona y Juan Vilaboa, (Coordinadores). Las formas de la política en la Patagonia. Buenos Aires, Biblos, 2007; Graciela Iuorno. "La provincialización de Río Negro, Interregno y conflicto de intereses nacionales y locales", en Martha Ruffini y Ricardo Freddy Masera, (Coordinadores), Horizontes en perspectiva. Contribuciones para la historia de Río Negro 1884-1955. Viedma, Legislatura de Río Negro, 2007; Martha Ruffini. "La Revolución Libertadora en el sur argentino. Persecución política y antiperonismo en río Negro". Revista e@latina, Vol.XI, № 41. Buenos Aires, 2012, pp. 37-58.
} 


\section{Tiempos antiperonistas en la Patagonia argentina}

debido a la pugna por la apropiación de la renta agraria. Sobre el final de su gobierno, el conflicto con la Iglesia Católica alarmó a los sectores más conservadores y al Ejército, en cuyo seno se estaba gestando una conspiración antiperonista. La conjunción de intereses militares, eclesiásticos y partidarios otorgaron legitimidad al desplazamiento del líder justicialista. El conflicto con la Iglesia Católica, la política petrolera oficial, la exacerbación de la violencia, el enfrentamiento faccioso y el ejercicio autoritario del poder fueron algunas de las razones alegadas para desencadenar la conspiración cívico-militar.

Con escasa resistencia, el gobierno peronista fue derrocado el 16 de septiembre de 1955, y se produjo la asunción del General Eduardo Lonardi, jefe de la sublevación en Córdoba. El tono conciliador de Lonardi, resumido en su famosa arenga "no hay vencedores ni vencidos", acercó al sindicalismo, otrora apoyo sustancial del peronismo, pero no evitó la emergencia de la llamada "resistencia obrera". ${ }^{2}$

Los hacedores de la Revolución -generales Lonardi, Aramburu y Contralmirante Isaac Rojas- se ocuparon en todo momento de crear un andamiaje explicativo de la acción realizada y del rumbo que debía tomar el nuevo gobierno. En primer lugar, buscaron auto-legitimarse a través del rol que le cabía a los militares como gestores de la revolución y ubicaron al golpe dentro de la historia nacional. En segundo lugar, trazaron un diagnóstico severo del gobierno precedente, al que llamaron "tiranía" y propusieron medidas de acción para eliminar todo vestigio del mismo.

Ante la población, procuraron justificarse interpretando que su accionar formaba parte de la responsabilidad histórica de las Fuerzas Armadas con el pueblo de la Nación. Conociendo su ilegalidad de origen, intentaron mostrar al golpe como un hecho legítimo, como una obligación histórica "de breve interinato", que coronaba la culminación de un clima de resistencia popular, de "rebeldía espiritual y material del pueblo sano de nuestra patria", que en la revolución corona la unión pueblo civil y pueblo armado lo que constituye "una verdadera empresa patriótica". Así presentaron a la revolución como nacida de "...la necesidad de poner fin al caos imperante y a las causas que lo originaron". ${ }^{3}$ En ese sentido el alzamiento armado era la ejecución de una voluntad social que emanaba de la comunidad misma y los militares fueron quienes interpretaron el "sentir del pueblo" y produjeron el golpe. En sentido gramsciano, los militares pretendieron actuar como "reserva del orden" cuando consideraron que la legalidad estaba amenazada, representando el pensamiento de las fuerzas políticas y sectores sociales antiperonistas y constituyendo así una voluntad activa que se impuso sobre la voluntad estatal hasta entonces hegemónica y la derrocó. ${ }^{4}$

\footnotetext{
2 Daniel James. Resistencia e integración. El peronismo y la clase trabajadora argentina. Buenos Aires, Siglo XXI editores, 2003.

${ }^{3}$ República Argentina. Libro Negro de la segunda tiranía .Decreto-ley n 14988/56. Buenos Aires, 1958, p 10. Anales de Jurisprudencia Argentina, Tomo XVI-A, Decretos, 1956, Proclama del 27 de abril de 1956, p. 1.

${ }^{4}$ Antonio Gramsci. Notas sobre Maquiavelo, sobre la política y el Estado moderno. Buenos Aires, Nueva Visión, 1987, p.89.
} 


\section{Martha Ruffini}

El objetivo revolucionario era "recuperar el sistema de vida civilizada occidental", que formaba parte de la tradición histórica argentina. En ese sentido el golpe hundía sus raíces en los inicios de la Nación. Para la retórica golpista la revolución se entroncaba con la gesta fundadora de Mayo de 1810 y tenía como jalón fundamental los principios e ideales de la Constitución de 1853, pacto constitucional del que la revolución de 1955 se consideraba heredera. Entre 1810 y 1853 el país había presenciado el surgimiento de lo que ellos nominaban como la "Primera Tiranía", con la que se aludía al gobierno de alcance nacional de Juan Manuel de Rosas. Al ser derrotado en la batalla de Caseros (1852), el pueblo condenó el despotismo y dictó la Constitución Nacional de 1853, "inspirada en el dolor padecido". ${ }^{5}$ Esta afirmación era sostenida con fuerza ya que la asociación despotismo vencido/nuevo pacto constitucional fue utilizada con frecuencia en función de uno de los objetivos primordiales del gobierno de facto que fue la derogación de la Constitución de 1949, de cuño peronista, y el restablecimiento de la vigencia de la Constitución liberal de 1853 y sus reformas.

La voluntad de provocar el golpe nacía de la esencia ideológica de los militares que ellos identificaban con la idea de democracia: "La sustancia democrática no está en su origen y forma de advenimiento sino en las razones éticas que lo determinan y en los medios que emplea para realizar los fines propuestos".6 Los aliados civiles que apoyaron el golpe formaban parte de "la opinión sana del país" eran fuerzas de "raigambre democrática" decididas a colaborar para el advenimiento de un futuro Estado Constitucional. En una aparente paradoja, los militares utilizaron en reiteradas ocasiones el concepto democracia diluyendo de su contenido la idea de pueblo participativo y reforzando su asociación con el orden y la armonía. Como bandera, esgrimían que algunas de las instituciones creadas respondían al objetivo de restablecer la soberanía popular y recuperar el verdadero sentido de la democracia, entre ellas la Junta Consultiva Nacional ${ }^{7}$ y la Junta de Defensa de la Democracia.

Otra manera de auto-legitimarse fue considerar que la legalidad del movimiento revolucionario se hallaba determinada por la ilegalidad del gobierno derrocado, al que pronto comenzaron a llamar "régimen depuesto". La revolución venía a libertar al pueblo de la opresión sufrida -de ahí su auto denominación como Libertadora- y a restaurar las libertades conculcadas. El diagnóstico realizado implicaba la condena a la tiranía vivida y la necesidad de reparación del equilibrio federal mediante la revitalización del federalismo constitucional genuino. Los militares venían así a restaurar el orden y corregir el rumbo de la Patria, que se había desviado de sus fines originales durante el peronismo. Así lo expresaban en la proclama del 7 de diciembre de 1955, en la que se aseguraba que su razón de ser era derrocar al

\footnotetext{
${ }^{5}$ República Argentina. Libro Negro..., Op.cit, p.p. 25-27.

${ }^{6}$ Presidencia de la Nación. Memoria del gobierno Provisional de la Revolución Libertadora. 1955-1958. Buenos Aires, 1959, p. 33.

${ }^{7}$ Estaba integrada por los socialistas Nicolás Repetto, Américo Ghioldi, Alicia Moreau de Justo, los radicales Oscar Alende, Oscar López Serrot y Miguel Ángel Zavala Ortiz, el socialista Américo Ghioldi y los demócratas progresistas Horacio Thedy y Julio Noble, entre otros.
} 


\section{Tiempos antiperonistas en la Patagonia argentina}

régimen de la "dictadura" como fin impulsor de la acción militar. Entre los objetivos se encontraba la necesidad de "desmantelar las estructuras y formas totalitarias de la sociedad y desintegrar el estado policial a fin de democratizar la sociedad y las instituciones argentinas". 8

Estas argumentaciones justificaban la proscripción electoral del Partido Justicialista y de su líder y la apertura del proceso de desperonización. Su determinación implicaba borrar al peronismo de la memoria colectiva, en suma, destruir sus vestigios para reconstruir lo que ellos consideraban una Nación quebrada y sin rumbo. Se apeló a la desperonización para constituirse como actores legítimos, intérpretes de la verdadera tradición nacional .El discurso emitido reflejó el "mercado de ideas" dominante que representaba el pensamiento de gran parte del antiperonismo reinante. ${ }^{9}$

La naturaleza misma del golpe de Estado contenía la violencia como parte constitutiva: la desperonización como meta implicó el ejercicio violento y represivo, que excedió la mera declamación. A pesar de la dificultad en sostener como compatibles la desperonización con la idea de pacificación del presidente Lonardi y las tensiones que esto generaba al interior del bloque gobernante, ${ }^{10}$ persecuciones, detenciones, fusilamientos fueron visibles manifestaciones de esa violencia estatal impulsada por el Estado que actúa como un gendarme, un "guardián nocturno" que se auto-asume como tutor del "orden deseado". La decisión de proscribir aparece así como manifestación de exclusión.

Pero esa exclusión debía justificarse ante la sociedad y los militares lo van a hacer en forma minuciosa. La puesta en escena del golpe implicó dar a conocer con dramatismo extremo el grado de corrupción imperante que fundaba -para ellos- el avasallamiento institucional. Para ello describieron con crudeza lo que consideraban una "dictadura degradada de honda inmoralidad" que significó un claro retroceso de la argentinidad al desconocer derechos y garantías ciudadanas. En la discursividad golpista, el pueblo aparecía como un actor pasivo durante el peronismo, engañado, un colectivo sometido y cargado de obsecuencia. El "servilismo incondicional" de funcionarios y legisladores se tradujo en una "masa de delitos, irregularidades, gérmenes del oprobio de un régimen siniestro" que "afirmó buena parte de su fuerza de cohesión subjetiva en el fanatismo de hombres y mujeres que lo sostuvieron".11 Como contraste, la Revolución Libertadora era "límpida, de rectos principios, democrática, sana y restauradora".

Interpretaban que el camino hacia la "dictadura" peronista se había gestado a partir del golpe de 1943, con la creación de la Secretaría de Trabajo y Previsión que marcó el "comienzo de la descomposición institucional orientada en el camino de la tiranía".

\footnotetext{
${ }^{8}$ Anales de Jurisprudencia Argentina, Tomo XVI-A, Decretos, 1956, Directivas Básicas del 7 de diciembre de 1955, pp. 2-3.

${ }^{9}$ O'Donnell, Guillermo y Philippe Schmitter. Transiciones desde un gobierno autoritario. Buenos Aires, Prometeo, 2010, pp. 41 y ss.

${ }^{10}$ María Estela Spinelli. Los vencedores vencidos...0p.Cit, pp.7-10.

${ }^{11}$ República Argentina, Memoria...Op.Cit, p. 34.
} 


\section{Martha Ruffini}

Perón era el tirano "corrupto y depravado" que había impuesto su voluntad al pueblo. Lo representaban como una figura ambiciosa, con procedimientos delictuosos e inmorales, demagogo y mal gobernante ya que "traiciono los ideales de la nacionalidad". Afirmaban que discursivamente, al criticar Perón el pasado nacional glorioso de nuestro país, rompió el vínculo existente entre las generaciones argentinas que la revolución venía a anudar nuevamente. Frente al golpe de 1955, Perón era un cobarde que había abandonado el poder y sus deberes como Comandante en Jefe ofreciendo a los militares una "rendición incondicional". ${ }^{12}$ De igual modo, afirmaban que el líder justicialista era el responsable de haber creado "jefaturas espirituales repugnantes a toda conciencia republicana ". Esta expresión era una inequívoca alusión a su esposa Eva, "el más extraordinario elemento de propaganda que tuvo el dictador",13 que los militares consideraban una mujer agresiva y espontánea pero le reconocían coraje e intuición política En alguna medida -decían- Eva se asemejaba a Encarnación Ezcurra, la esposa del gobernador Rosas. Al igual que esta figura, la muerte temprana de Eva "evito al país más graves perturbaciones en el período final de la tiranía".14

\section{El gobierno de facto y la decisión de investigar}

Con una acción envolvente, los militares operaron en dos sentidos. Por un lado, ensayaron una estrategia de integración subordinada de los partidos políticos, cómplices del pacto de proscripción. En octubre de 1955, se anunció la creación de una Junta Consultiva Nacional de carácter asesor integrada por fuerzas representativas de diferentes corrientes de opinión y se sugirió replicar esta organización en las provincias. A pesar de su breve vigencia, esta Junta Consultiva fue considerada el brazo civil del movimiento revolucionario. ${ }^{15}$

Simultáneamente y mediante decreto-ley se crearon dos comisiones nacionales de investigación: la Comisión Investigadora del enriquecimiento ilícito y la actuación de personas que ejercieron funciones legislativas desde 1946, y la Comisión Nacional de Investigaciones, creada el 7 de octubre de 1955. Su objetivo era determinar la responsabilidad de figuras vinculadas con la administración justicialista con el objetivo de "reintegrar a la administración pública la moralidad, la honestidad y el prestigio que deben caracterizar el ejercicio de sus funciones", para lo cual se proponía investigar las "irregularidades del régimen depuesto cometidas por funcionarios o por particulares" en todas las ramas de la administración

\footnotetext{
${ }^{12}$ Estas afirmaciones fueron tomadas de los Considerandos del Decreto -Ley $\mathrm{N}^{\circ} 42$ del 25 /9/1955 por el que el Presidente Provisional de la Nación asumió las facultades legislativas del Congreso Nacional.

${ }^{13}$ República Argentina, Memoria del gobierno..., Op.cit, pp.34-44; República Argentina, Libro Negro..., Op.cit, pp.9-22.

${ }^{14}$ República Argentina, Libro Negro..., Op.Cit, p. 43.

15 María Sáenz Quesada. La Libertadora. Historia pública y secreta.1955-1958, Buenos Aires, Sudamericana, 2007, p. 139.
} 


\section{Tiempos antiperonistas en la Patagonia argentina}

pública. ${ }^{16}$ Dotada de facultades $\mathrm{y}$ atribuciones judiciales $\mathrm{y}$ legislativas excepcionales, ${ }^{17}$ estaba integrada por cinco miembros -tres de ellos pertenecientes al orden castrense- y se hallaba bajo la dependencia directa del vicepresidente de la Nación Contraalmirante Isaac Rojas. La presidía el Contralmirante Leonardo Mc.Lean, ex director de la Escuela Naval Militar. De su actividad se derivaron 60 comisiones -generales y específicas- que abarcaban un amplio abanico de indagaciones. ${ }^{18}$

Para los militares, esta Comisión Investigadora constituyó un "imperativo revolucionario" basado en la necesidad de restablecer la legalidad que se consideraba perdida durante el peronismo. ${ }^{19}$ Mac Lean llegó a afirmar que las Comisiones Investigadoras "debían realizar una limpieza total de los gérmenes del oprobio" y "descubrir para su extirpación hasta donde fuese posible los gérmenes de la traición".20 Esta afirmación prefigura las argumentaciones vertidas por las dictaduras militares de 1966 y 1976 y revela el progresivo empoderamiento del orden castrense de estas nociones que formaron parte del régimen estatal de desaparición de personas a partir de la década de 1970.

Las disidencias al interior de las filas golpistas y el vínculo con el movimiento obrero del presidente Lonardi fragmentaron el sector antiperonista del gobierno, provocando la renuncia de la Junta Consultiva Nacional. Con el liderazgo de la Marina, un movimiento interno produjo el desplazamiento de Lonardi por el general Pedro Eugenio Aramburu el 13 de noviembre de 1955, dando por terminado el experimento de la "transición tolerante". ${ }^{21}$

Como correlato anunciado, se endureció la postura con respecto al peronismo. Se reprimió la actividad sindical, las comisiones investigadoras intensificaron su labor y se produjo la inhabilitación gremial y política del justicialismo y de sus figuras más representativas. En esta instancia cobró mayor relevancia el ala dura de los militares, simbolizada en la figura del vicepresidente de la Nación Contralmirante Isaac Rojas. La desperonización cobró forma normativa mediante el decreto № 4161 del 5 de marzo de 1956, 22 que prohibió lo que consideraban "elementos de afirmación ideológica o de propaganda peronista”. Este decreto originó el marco legal de la proscripción, justificó la represión y procuró borrar la memoria social

\footnotetext{
16 República Argentina, Libro Negro..., Op.Cit, pp.7-8.

${ }^{17}$ La Comisión Nacional de Investigaciones podía detener personas, allanar domicilios, recoger pruebas e intervenir libros de contabilidad de organismos públicos y privados.

${ }^{18}$ Las comisiones de investigación eran de diferentes tipos. Algunas eran generales -comisiones que investigaban el accionar de cada ministerio- y otras específicas, vinculadas con la actuación de personas (Jorge Antonio, Alberto Teissaire, ex legisladores peronistas), organismos nacionales (Banco Central, Banco Hipotecario Nacional, YPF, Aerolíneas), espectáculos (cine, teatro y radio), instituciones y asociaciones vinculadas directamente con el peronismo (Escuela Superior Peronista, Fundación Eva Perón, Comisión Pro-Monumento a Eva), entre otras.

${ }^{19}$ República Argentina, Libro Negro..., Op.CIt, p.11.

20 Ídem, pp.13-14.

21 María Estela Spinelli. Los vencedores...op.cit, p. 55.

22 República Argentina, Anales de Jurisprudencia Argentina Tomo XVI-A, Decretos, pp.241-242.
} 


\section{Martha Ruffini}

para desarticular la identidad política peronista. ${ }^{23}$ La represión ejercida motorizó diversas respuestas. Militares, ex funcionarios peronistas y dirigentes sindicales comenzaron a dar forma a lo que se ha llamado "la resistencia peronista", que se prolongó hasta mediados de la década de 1960.24 Pero la espiral represiva continuó su marcha ascendente. Este proceso que abarcó todos los aspectos de la vida política nacional se agudizó en junio de 1956 con el levantamiento de los generales de división Juan José Valle y Raúl Tanco, que fue desactivado rápida y drásticamente al decidir el gobierno de facto el fusilamiento de gran parte de los militares y civiles sublevados y la implantación de la Ley Marcial que instaló la pena de muerte por razones políticas.

En todo el país, las Comisiones Investigadoras trabajaron para cumplimentar los fines de su creación. Al cesar su labor habían analizado más de 15.000 notas y expedientes, elevado 314 sumarios y puesto a disposición de la Justicia 1045 procesados. $^{25}$ En abril de 1956 Rojas ordenó interrumpir el trabajo de las comisiones, alegando la premura de obtener los datos necesarios para el armado de los libros que darían a conocer los hechos delictuosos. Pero se puede pensar también en presiones empresariales y de las corporaciones económicas nacionales e internacionales ante los hechos investigados. ${ }^{26}$

\section{El gobierno de la “Revolución Libertadora” y la Patagonia}

Como se ha expresado, la Revolución Libertadora postergó la ejecución de la ley $\mathrm{N}^{\circ}$ 14.408/55 de creación de nuevas provincias patagónicas dictada durante los últimos meses del gobierno peronista. En su reemplazo, el gobierno provisional dictó un Estatuto para el gobierno y administración de las provincias que tendría vigencia hasta la sanción de la Constitución Provincial. ${ }^{27}$ Para Tierra del Fuego fue dictado un Estatuto especial en 1957 y se creó una gobernación militar dependiente de la presidencia de la Nación, manteniendose como Territorio Nacional hasta 1991. En el caso de las provincias Chubut y Patagonia la transición fue más compleja. Al disolverse la Gobernación Militar de Comodoro Rivadavia (1944-55),28 su parte norte quedo para Chubut y la parte sur para Patagonia, provincia que además debió administrar temporalmente la ex gobernación de Tierra del Fuego. En 1956 la Provincia Patagonia recobró su antigua denominación de Santa Cruz.

\footnotetext{
${ }^{23}$ Catalina Scoufalos. 1955. Memoria y resistencia. Buenos Aires, Biblos, p. 50.

${ }^{24}$ Como es conocido, la resistencia clandestina se manifestó de múltiples maneras: atentados, incendios intencionales, sabotaje, ataques a símbolos de la "Revolución Libertadora", fabricación casera de bombas y artefactos explosivos.

${ }^{25}$ República Argentina, Libro Negro..., Op.Cit, p.14.

${ }^{26}$ María Sáenz Quesada. La Libertadora..., Op.Cit, pp. 155 y ss.

${ }^{27}$ República Argentina, Anales de Jurisprudencia Argentina...Op. Cit, pp. 755-758.

${ }^{28}$ Los habitantes de Comodoro Rivadavia no aceptaron la incorporación a Chubut y ensayaron varias alternativas. En enero de 1956 a través de los medios de prensa y el envío de petitorios, propusieron integrarse totalmente a la provincia Patagonia o bien, crear una nueva provincia que contuviera los límites de la antigua gobernación militar.
} 


\section{Tiempos antiperonistas en la Patagonia argentina}

A poco de asumir y en función de la decisión de desperonizar la sociedad, los interventores federales recibieron la orden de eliminar los nombres de Perón y Eva de calles, plazas, ciudades y monumentos, suprimir feriados celebratorios vinculados con el peronismo y los libros de texto alusivos de los planes de estudio. Los primeros pasos colocaron a todo el personal de la gobernación bajo sospecha y fueron declarados en comisión, medida que en algunos casos como la Provincia Patagonia no fue levantada hasta octubre de 1956. Fueron intervenidos la mayoría de los municipios territoriales -en Neuquén la totalidad-y de las comisiones de fomento al igual que algunas comisarías y subcomisarías. Los jueces de paz fueron reemplazados y una minoría fue reconfirmada en el cargo. En Rio Negro varios organismos fueron intervenidos -mayoritariamente establecimientos escolares, hospitales y delegaciones del ministerio de Trabajo y Salud- o disueltos, como por ejemplo las Cámaras de Alquileres de General Roca, Villa Regina, Bariloche, Ing. Jacobacci, Bariloche y Rio Colorado. En la Provincia Patagonia se intervino el Yacimiento de Río Turbio y ramal ferroviario, la delegación Rio Gallegos de la CGT, la emisora LU12 Rio Gallegos, el Círculo Policial de Socorros Mutuos y la Confederación General de Profesionales. ${ }^{29}$

Simultáneamente, los interventores debían instalar las Comisiones Investigadoras en sus provincias. ${ }^{30}$ El objetivo era "mostrar a la Nación aquellos hechos que habiendo constituido una corrupción administrativa o moral sean capaces de gravitar en la opinión publica en forma tal que conmuevan profundamente toda esta organización de tipo político-delictiva que accionaba en todo el país durante doce años". Reservadamente se le sugería al interventor de Río Negro que investigara cinco o seis tipos de irregularidades "que justifiquen plenamente la razón de ser de esta comisión investigadora"; se infiere que el interventor debía buscar y denunciar y si no hallaba cargos para acusar, crear los hechos, sugerencia implícita que trasunta el verdadero espíritu de la nota. ${ }^{31}$

Las Comisiones Investigadoras fueron organizadas rápidamente en el sur. En la mayoría de los casos las presidían militares como el Capitan de Navío José María Guzman en Patagonia, el Teniente Angel Barbieri en Neuquén, el teniente de Navío Alberto Schneidewind en Chubut -posteriormente reemplazado por Julio Ibarguren, quien manifestaba que deben "juzgar a los ciudadanos que delinquen o cooperaron en la subversión del orden republicano y en la deformación de las conciencias"-.32 Sus

\footnotetext{
${ }^{29}$ La Voz del Pueblo, Rio Gallegos, 11/11/1955, p.1.

30 En Neuquén el Interventor Federal fue el capitán de navío Ricardo Hermelo, quien actuó hasta noviembre de 1955; en Río Negro el Teniente Coronel Gualberto Wheeler; en Chubut el Capitán de Fragata Raúl Sidders desde octubre de 1955; en la provincia Patagonia el Capitán de Fragata Alejandro Galarce, sucedido por el Teniente de Navío Miguel Muro.

31 Archivo General de la Nación, Archivo Intermedio, Fiscalía Nacional de Recuperación Patrimonial, Clasificación y custodia de actuaciones. Comisiones Provinciales (en adelante AGN-FNRP), provincia de Río Negro, legajo № 1066, Directivas para la intervención Federal, 8 de noviembre de 1955. Véase también Archivo Histórico de la Provincia de Río Negro. Sección Administración de Gobierno. Expedientes Generales (en adelante AHP-RN), año de 1955, Caja № 18-B, Expediente I-331, Nota del ministro del Interior al interventor de Río Negro, 18 de octubre de 1955.

${ }^{32}$ AGN-FNRP, Caja N 1, nota del 6/1/1956, Comisión Central de Chubut a Leonardo Mc Lean, f 2.
} 


\section{Martha Ruffini}

integrantes eran figuras locales, vinculadas a corporaciones o a partidos como el radicalismo en Neuquén y en Río Negro, provincia en la que tambien actuó el Partido Socialista. La Comisión rionegrina fue presidida por Enrique Geddes y en ella participó el abogado radical Edgardo Castello, primer gobernador constitucional de Rio Negro en 1958. En cambio en Patagonia fue notoria la presencia de militares en las comisiones.

Los Interventores Federales tenían la facultad de crear la cantidad necesaria de subcomisiones, ya sea de carácter permanente o por breve tiempo. En Río Negro hubo 12 subcomisiones; Neuquén 3 subcomisiones -Zapala, Neuquén y San Martín de los Andes- mientras que en Chubut hubo 17 sub comisiones y colaboraron con ellas 73 personas. La provincia Patagonia tuvo 9 subcomisiones en las principales localidades, una Comisión Provincial de Investigaciones sobre importación al sur del paralelo 42 y una Sub Comisión Investigadora de Aduana y Contrabando, en ambos casos creadas debido a las múltiples denuncias de irregularidades en el transporte de productos. ${ }^{33}$

En líneas generales las comisiones investigadoras recibieron amplia colaboración de la sociedad civil y sus instituciones representativas. Según el presidente de la Comisión de Neuquén Barbieri, la colaboración social se explica por las "ansias retenidas de la gente para que por fin bajo el nombre de Revolución Libertadora se les hiciera justicia volviendo al país a la normalidad que tanto aspiraba", lo que justificaba la cantidad de denuncias realizadas. ${ }^{34}$

La sociedad se movilizó y denunció con un tono no exento de revancha. En Neuquén se registraron varias denuncias de particulares contra policias, personal de las escuelas y ferroviarios. En esta provincia llama la atención un importante número de denuncias de subalternos contra superiores, lo que señala el grado de persuasión de las autoridades revolucionarias sobre la totalidad de los empleados, animando la delación y la denuncia. En la provincia Patagonia hubo denuncias de vecinos sobre empleados de Aduanas, jueces de paz, comisionados municipales y directores de escuela. No todas las denuncias tenían resolución favorable. En el caso de Neuquén la falta de prueba era suficiente para archivar la causa o la pertenencia de los denunciados al orden castrense alejaba el riesgo de investigación.

Una vez producida la revolución, representantes del clero, autoridades civiles y de organizaciones expresaron la adhesión al nuevo gobierno. En Neuquén y en las ciudades rionegrinas de Viedma y General Roca se realizaron celebraciones populares -caravanas de vehículos y hasta carrozas adornadas con importante participación de jóvenes estudiantes festejando la caída del gobierno peronista-. Estos actos festivos estuvieron acompañados de episodios violentos y de vandalismo contra estatuas, placas, locales justicialistas -con quema de archivos- $y$

\footnotetext{
${ }^{33}$ Archivo Histórico de la provincia de Santa Cruz. Fondo Gobernación de la provincia. Sección Provincia Patagonia (en adelante ASC-PP) Legajo 2, Expediente 1361, 15 /2/1956; Expediente 1749C, $15 / 3 / 1956$.

${ }^{34}$ Archivo General de la Nación, Fiscalía Nacional de Recuperación Patrimonial, Comisión Nacional de Investigaciones, (en adelante AGN- CNI), Memorias de las comisiones Provinciales, Caja 13, Memoria original de Neuquén, $\mathrm{f} 1$.
} 


\section{Tiempos antiperonistas en la Patagonia argentina}

periódicos locales como Bariloche, de la localidad homónima, cuyo local fue destruido. ${ }^{35}$ En Gaiman (Chubut) a los pocos dias de la revolución se registró una manifestación popular en homenaje a las Fuerzas Armadas y al gobierno revolucionario. ${ }^{36}$ En Río Gallegos (provincia Patagonia) fue aprovechada la llegada de un torpedero para rendir homenaje al conjunto de las Fuerzas Armadas.

Las comisiones investigadoras recibieron apoyo de empleados que donaron su tiempo libre para investigar como tambien de organizaciones económicas que expresaron su deseo de colaborar, como por ejemplo, la Federación Económica de Comodoro Rivadavia o el Colegio de Abogados de General Roca. Del mismo modo, la creación de Juntas Consultivas en las provincias contó con la participación de las organizaciones económicas e instituciones financieras y educativas. A modo de ejemplo, en Patagonia la Junta Consultiva tuvo representantes de corporaciones como la Sociedad Rural de Río Gallegos, la Cámara de Comercio e Industria, la Federación Económica de la Provincia,la CGT regional, el Banco Nación, YPF y el Colegio Nacional entre otros. ${ }^{37}$ En Río Negro la Junta Consultiva estuvo integrada por dos representantes de los partidos políticos y de las fuerzas independientes de la provincia, actuando el ministro de gobierno como su presidente. Participaron en ella siete integrantes, dos por cada fuerza política -partidos Socialista, Demócrata Nacional, Demócrata Cristiano- y un representante por las fuerzas independientes. El radicalismo rionegrino aceptó integrar las comisiones investigadoras y la subcomisión provincial liquidadora de los bienes del ex Partido Peronista creada en enero de 1956, pero no participó de esta Junta quizá para no aparecer directamente ligado a una tarea gubernativa de estrecha colaboración con la intervención.

Pero hubo también muchas denuncias de particulares o grupos de vecinos que se dirigían directamente al interventor, a los ministros o a la Comisión Investigadora Provincial o local. Solicitaban la intervención de organismos alegando la presencia de figuras vinculadas con el justicialismo que constituían una verdadera "amenaza y peligro para la moral". Los motivos eran por acciones o dichos de los denunciados, ya sea autoridades, empleados o instituciones pero también por omisiones -la inasistencia a un acto patrio por ejemplo- o expresiones orales de difícil probanza. Se los acusaba de vínculo -aunque sea emocional- con el gobierno justicialista y la persona de Perón o por presunción de connivencia con el mismo ya sea por ausencia de palabras a favor del gobierno de facto. No se presentaba prueba alguna y bastaba la declaración para que la policía iniciara una investigación. En ocasiones, las comisiones investigadoras y sus filiales dieron pie para que asuntos de índole comercial o personal intentaran ser resueltos a través de las mismas como denuncias por cobro de deudas, multas, desalojo de tierras o reyertas personales

\footnotetext{
${ }^{35}$ La Nueva Era, Carmen de Patagones, 1/10/1955, p.3; Río Negro.General Roca, 23/9/1955, p. 1, entre otros.

36 Archivo Histórico de Chubut, Fondo Documental Gobernación del territorio del Chubut, 18851957, Expedientes Microfilmados (en adelante AHCH), Rollo $\mathrm{N}^{\circ} 1229$, Nota del interventor Federal al Ministro de Interior y Justicia, 24 de octubre de 1955; Rollo 1224, Expediente 2192, nota del 24/9/1955.

${ }^{37}$ ASC-PP, Legajo 3, Expediente 8019, Decreto $N^{\circ} 28,9 / 10 / 1955$.
} 


\section{Martha Ruffini}

Asimismo personal despedido durante la gestion peronista por faltas en el desempeño de sus tareas aprovechó el cambio de orientacion política para alegar discriminación politica y antiperonismo.

Cuando la sospecha era de connivencia y para prevenir cualquier reacción contra el gobierno de facto, los resultados de las denuncias implicaban frecuentemente el traslado o cesantía o la detención como presos políticos en la cárcel de Viedma o en la de Río Gallegos, motivado la queja de las autoridades gubernativas ante esa presencia: "se extendieron de inmediato en esa capital las redes sutiles de las comunicaciones clandestinas, las familias o amistades de los confinados que vinieron periodica o permanentemente a Rio Gallegos serán células en potencia a las que será imprescindible vigilar".38

Llama la atención que en Río Negro grupos de vecinos y autoridades municipales colaboraron activamente en la represión mediante la creación de comandos civiles revolucionarios o grupos de apoyo al gobierno de facto que pusieron bajo la dependencia de la policía local. Su función era vigilar, delatar y castigar, generando acciones con algún grado de violencia. ${ }^{39} \mathrm{En}$ algunos casos como los comandos civiles organizados en Ing.Jacobacci y Maquinchao, su emergencia podría estar relacionada con los sucesos de junio de 1956; en otros casos como la Junta Pro Defensa de la Revolución Democrática de General Roca, resultan anteriores y aparecen a fines de 1955. Esta Junta emitió una amplia solicitada explicitando su constitución y objetivos y registrando múltiples adhesiones. En sus considerandos advertimos que se auto-asignó un rol de vigilancia, delación y control tanto de la opinión pública como de las autoridades como una forma de prevenir acciones de los "dirigentes desplazados". 40

Otro actor social importante fue la Iglesia Católica, estrecha aliada del régimen militar. Pero su postura no fue uniforme ya que dependió de la adhesión personal de los sacerdotes -mayoritariamente de la orden salesiana de Don Bosco-instalados en el sur. Algunos con militancia activa, difundiendo panfletos y realizando denuncias, tuvieron un claro compromiso con uno u otro bando. A modo de ejemplo, mientras en Neuquén una cesantía masiva de obreros petroleros en Plaza Huincul motivó la intervención del sacerdote salesiano Ernesto Zsanco en favor de los despedidos, en la Provincia Patagonia, en el paraje Los Antiguos, el sacerdote Natalio Astolfo realiza una serie de denuncias contra el presidente de la Comisión de Fomento, el director del Hospital Local, enfermeros y maestras. Su fervor con el gobierno de facto lo expresa al decir: "La Escuela de Perito Moreno es un nido de viboras peronistas...que los trasladen a un lugar donde, en nuevo ambiente, puedan rehabilitarse para bien suyo y nuestro". 41

\footnotetext{
${ }^{38}$ ASC-PP, legajo 4, Expediente 9863-C, Nota del interventor Federal al Ministro del Interior, 9/1/1956, f 2; AHP-RN, año de 1955, Caja № 18- B, Expediente C-421, 19 de octubre de 1955.

${ }^{39}$ AHP-RN, año de 1956, Caja № 6, nota del comisario de Maquinchao al Jefe de Policía, 18 de junio de 1956.

${ }^{40}$ AGN-CNI, provincia de Río Negro, legajo № 1068, 5 de diciembre de 1955.

${ }^{41}$ ASC-PP, Legajo 1, Expediente 3333-A, 3 de enero de 1956.
} 


\section{Tiempos antiperonistas en la Patagonia argentina}

Las grandes distancias significaron muchas veces un importante obstáculo para la labor de estas comisiones. Pueblos separados por varios kilometros y las dificultades en las comunicaciones implicaron una tarea lenta y dificil, que demoró la conformacion de las subcomisiones. El compromiso de la sociedad civil pasaba por la denuncia y el ofrecimiento de pruebas, no así por la participación efectiva, como refieren en Chubut. ${ }^{42}$ Por otra parte, un inconveniente de dificil superación y que provenía de la etapa territorial era la existencia de oficinas del Estado Nacional con sus propias autoridades que respondían directamente a funcionarios nacionales. Al no haberse dispuesto la preeminencia de los interventores federales y por ende sus comisiones de investigación sobre los mismos, estos alegaban desconocimiento de la autoridad provincial, dilatando las respuestas solicitadas, aspecto advertible como comentario o queja en notas e informes de Chubut y Neuquén.

Además, no siempre existía personal disponible para integrar las sub comisiones. En la Provincia Patagonia no se pudo conformar la sub comisión Tierra del Fuego porque no había integrantes militares disponibles para asumir el cargo sin dejar su tarea habitual. En Río Negro, Enrique Geddes manifestaba que la labor de la Comisión Provincial había sido eficiente, ardua pero obstaculizada por la gran extensión de la provincia y la necesidad de constituir subcomisiones cuya supervisión recaía sobre la Comisión Provincial que se vio considerablemente recargada de trabajo. Opinaba que las dificultades operativas de las sub-comisiones estribaban en la composición y el carácter no rentado de los miembros, lo que ocasionaba que hubiera un reducido número de horas diarias destinadas a analizar los expedientes. ${ }^{43}$

Por otra parte, se advirtieron disidencias al interior de las comisiones investigadoras. En Patagonia renunciaron todos los integrantes de la subcomisión del Puerto Santa Cruz disconformes con decisiones tomadas por la Comision Investigadora Provincial sobre la permenencia de notorios dirigentes justicialistas en sus cargos. ${ }^{44}$ En la sub-comisión rionegrina de Allen, dos de sus integrantes fueron acusados de propiciar despidos de personal en el hospital regional para negociar los cargos; en otros casos la comisión se extralimitó -como en Ing. Jacobacci- irrumpiendo en un establecimiento escolar para revisar carteras y mochilas de los alumnos y verificar si portaban retratos o libros del peronismo. El justificativo de la Comisión fue que "era necesario atemorizar a los niños para desperonizarlos". Las deficiencias en las investigaciones y estos hechos de corrupción motivaron el envío del secretario del ministerio del Interior Rafael Gallo

\footnotetext{
${ }^{42}$ AGN-FNRP, Comisiones Provinciales, Caja 1, provincia de Chubut, nota del 31 de marzo de 1956, Julio Ibarguren a Leonardo Mc Lean.

43 Ídemm, Nota de Enrique Geddes al presidente de la Comisión Nacional de Investigaciones del 16 de abril de 1956, p.750.

${ }^{44}$ ASC-PP, Legajo 1, Expediente 1894-C, 17 de marzo de 1956.
} 


\section{Martha Ruffini}

para realizar averiguaciones o en ocasiones, la incorporación del comisario local como preventor en todas las actuaciones. ${ }^{45}$

La Comisión Investigadora Nacional controlaba estrechamente las actuaciones de sus filiales provinciales solicitando en forma permanente novedades y estado de las investigaciones y recordando las medidas a tomar, fundamentalmente la información con antelación en los casos de allanamientos y secuestro de bienes. ${ }^{46}$ Los expedientes se resolvían en el lapso aproximado de dos meses, recabándose informes, tomando declaraciones y agregándose pruebas.

La atención inicial se puso en los ex funcionarios de los territorios nacionales, objeto preferencial de la investigación. En Neuquén fueron procesados por malversación de caudales públicos, dilación de justicia y falsificación de documentos el ex gobernador Pedro Luis Quarta (1952-1955), el secretario de la gobernación Claudio Robiglio y siete funcionarios y empleados. Asimismo, fueron acusados de desvío de fondos municiaples al Partido Peronista e irregularidades administrativas el ex Intendente de Neuquén Eduardo Cortez Rearte, el ex secretario Tesorero Juan Carlos Sobisch y el Contador Raul Pintos quienes conjuntamente con la delegada del Partido Peronista Femenino Amelia de Scalia quedaron detenidos. ${ }^{47}$

En Río Negro fueron investigados ex gobernadores como Miguel Montenegro, quien fue gobernador entre 1946 y 1949 y Emilio Belenguer (1949-1955). Emilio Belenguer fue investigado, detenido y juzgado. Se lo investigó por el uso de automóviles oficiales para fines propagandísticos del peronismo en Río Negro y en el distrito Villarino de la provincia de Buenos Aires; la utilización de empleados de la gobernación, materiales de construcción, maquinarias, muebles y otros bienes del Estado para su chacra en Río Colorado. ${ }^{48}$ En la investigación quedaron involucrados el ex ministro de Gobierno Juan Paolini -acusado de utilizar fondos públicos para el financiamiento de las actividades del partido justicialista, utilización de bienes del Estado para viviendas particulares y solicitud de facturas de favor- y el ex contador de la gobernación Vicente Rossi, cesanteado y denunciado por malversación de caudales públicos por el manejo de 250 expedientes de infracciones municipales. ${ }^{49}$ El ex Inspector de policía y jefe de la comisaria de Viedma Ricardo Mauri también fue alcanzado por la investigación, ya que fue denunciado por maltrato, utilización de automóviles oficiales y personal de bomberos para tareas agrícolas en su chacra particular. Los hijos del ex gobernador -Héctor y Emilio- fueron inicialmente

\footnotetext{
${ }^{45}$ AGN-FNRP, provincia de Río Negro, Legajo № 1070, Nota del 27 de diciembre de 1955; legajo № 1068, 14 de abril de 1956; legajo № 1067, Libro Copiador de la Comisión Provincial, 11 de noviembre de 1955, f 69 y 27 de diciembre de 1955, f 245 entre otros.

${ }^{46}$ AGN-CNI, provincia de Río Negro, legajo № 1066,"Normas básicas a seguir por las Comisiones Investigadoras y las sub-Comisiones", 21 de octubre de 1955.

${ }^{47}$ AGN-FNRP, Caja 1, Neuquén, Expediente 8989-D, 20 de diciembre de 1955; Archivo General de la Nación. Archivo Intermedio. Comisión de Ordenamiento de Archivos. Expedientes Secretos, Confidenciales y Reservados (en adelante AGN-ESCR), Caja 132, Nota del 8/2/1956 al ministro de gobierno de Neuquén sobre irregularidades en la Municipalidad de Neuquén.

${ }^{48}$ AHP-RN, año de 1955, Caja № 18-D, expediente C- 1196, 9 de octubre de 1955.

${ }^{49}$ AGN-FNRP, provincia de Río Negro, legajo № 1067, Informe reservado, Nota de Enrique Geddes al Interventor Gualberto Wheeler, 9 de enero de 1956, f 303.
} 


\section{Tiempos antiperonistas en la Patagonia argentina}

cesanteados de sus cargos en la gobernación, posteriormente afectados a otras reparticiones, y finalmente el interventor solicitó su salida de la provincia. ${ }^{50}$

En Chubut fueron investigados tanto ex gobernadores civiles como el abogado José Eduardo Picerno ( 1950-1951) y Hector Perurena (1952-1955) como así también el Gral. José Fernando Carlés, ex gobernador militar de Comodoro Rivadavia (19511953) y el secretario de la gobernación Cnel. Gabriel Bidone. En el caso de Carlés estaba imputado de peculado, malversación de caudales públicos, defraudación y contrabando a Chile de mercaderías. Este delito involucró al secretario Bidone, acusado de coacción a las autoridades aduaneras. Según Julio Ibarguren, en el caso de la ex gobernación de Comodoro se acumularon abundantes pruebas que fueron giradas a la Justicia. Pero la solicitud de interdicción de bienes a los presuntos responsables realizada al Interventor Federal quedó sin respuesta. ${ }^{51}$

En la provincia Patagonia fueron investigados los ex gobernadores de Santa Cruz el coronel Rafael Lascalea (1946-1951), el odontólogo Angel Carnota (1951-1952) y Tomás Fernández (1952-1955) sin resultado concreto ya que al cesar las comisiones la investigación estaba en curso.

Las medidas tomadas por los interventores muchas veces como iniciativa propia, otras a sugerencia del gobierno de facto o de la Comisión Provincial de Investigaciones constituyeron un arco que iba desde los sumarios administrativos, la detención, la toma de declaraciones, la suspensión en el cargo, el traslado o la cesantía y exhoneración. Los causales alegados fueron la militancia en el justicialismo, fundamentalmente en Unidades Básicas y en los Comandos Territoriales; la impresión y difusión de propaganda partidaria, el uso de bienes del Estado en beneficio del Partido Peronista; la asistencia a cursos doctrinarios fundamentalmente de la Escuela Superior Peronista- o el dictado de charlas sobre doctrina o medidas del gobierno justicialista. Mientras el gobierno alentaba la delación y la denuncia, se investigaba a aquellos justicialistas que habían delatado a compañeros de trabajo como antiperonistas. En este sentido las que recibieron las mayores acusaciones fueron las delegadas censistas y las maestras. En el caso de las mujeres, haber desempeñado el rol de delegadas censistas o militantes de las Unidades Básicas Femeninas inmediatamente las ponía bajo sospecha e investigación.

En algunos casos se hacia alusión a la adhesión por omisión -no denunciar, encubrir, la adscripción simbólica- portar el escudo peronista, tener fotos de Perón y Eva en los domicilios particulares y estafetas de correo, o tareas de delación y espionaje durante el gobierno peronista, ocultamiento de información y documentación.En algunos casos extremos se iniciaba la investigación sobre personas que eran señaladas por "hablar bien del peronismo", entonar canciones partidarias en oficinas públicas o mantener un concepto poco positivo en el ámbito civil. En la

\footnotetext{
50 AHP-RN, año de 1955, Caja no 18-E, Expediente I-1722, Nota del interventor de Río Negro al director general del ministerio del Interior, 23 de noviembre de 1955.

${ }^{51}$ Ibidem, nota de la Comisión Central Investigadora del Chubut a Leonardo Mc Lean, 16 de marzo de 1956.
} 


\section{Martha Ruffini}

Provincia Patagonia fue denunciado el Juez de Paz de San Julian Pedro Mariottini por varios vecinos porque "se indignó al enterarse de la caída de Perón". 52 En otras ocasiones, para obtener el desplazamiento del cargo se aludía en general a la necesidad de reorganización de los cuadros de la administración o en casos particulares a negligencia, apatía o irregularidad en el desempeño de las funciones o simplemente "hablar mal del interventor federal", siendo mínima la cantidad de justificaciones que alegan cargos cobrados pero no trabajados.

Las cesantías fueron importantes en número y se dieron mayoritariamente en el área educativa -directores de escuela y maestras-, salud -directores de hospitales y médicos-,agentes de policia, empleados de ministerios, oficinas de correo y municipales. En Neuquén la información oficial mencionó que no había habido despidos en los tres ministerios de la provincia -Gobierno,Economía y Acción Social-, pero se advierte que la Intervención Federal solicitó la remoción de funcionarios y empleados de la administración nacional en la provincia, contabilizándose solamente 25 traslados en la Oficina de Correos. En Rio Negro, se registraron cesantías de directores de establecimientos escolares y docentes o en su defecto traslados compulsivos, motivando a través de la prensa a la ciudadanía a colaborar indicando personas o instituciones que debían ser investigadas. En Chubut las cesantías fueron numerosas en la policia, personal municipal y correo; en Patagonia y Neuquén abarcaron un amplio campo de la salud, municipal, educativa y judicial. En muchas ocasiones los cesanteados alegaban haber mantenido un vinculo forsozo con el Partido Justicialista y haber participado para no perder el puesto de trabajo. En ese caso se solía recurrir a otros testigos que aseveraran el comportamiento neutral del cesanteado pero con pocas excepciones no lograban recobrar su cargo.

La vigilancia se extendió por toda la población. Por orden de los interventores federales, se fotografiaban a los asistentes a ceremonias religiosas, actos y reuniones incluso las convocadas por el gobierno militar. Se registraron cementerios -como el de Neuquen- en busca de material peronista enterrado, casas, chacras y unidades básicas justicialistas. Los medios de prensa también fueron perseguidos, controlados y censurados. A modo de ejemplo, el director del periódico Bariloche Andrés Castro y su esposa sufrieron embargo de bienes y Castro quedó detenido por disposición de la Comisión Investigadora local. ${ }^{53}$ En algunas provincias hubo solicitudes de expulsión. Fue el caso de en la Provincia Patagonia sobre Pablo Imboden de Ushuaia, Rector del Colegio Nacional, Director de la Escuela $\mathrm{N}^{\circ} 1$, presidente de la Biblioteca Provincial Sarmiento y fundamentalmente Presidente de la Agrupación Descamisados. Fue declarado persona no grata, bloqueados sus

\footnotetext{
${ }^{52}$ ASC-PP, Expediente 1288-C, elevan actuaciones de la subcomisión de San Julián, 15/2/1956.

${ }^{53}$ AGN-CNI, Río Negro, legajo № 1067, Libro Copiador de la Comisión Investigadora Provincial, nota de Abel Castro al interventor de Río Negro, 3/1/1956, f 270.
} 


\section{Tiempos antiperonistas en la Patagonia argentina}

fondos, detenido por exacciones ilegales y fraude y expulsado de la provincia junto con su esposa, acusada de utilizar a sus hijos pequeños para delación. ${ }^{54}$

En las provincias patagónicas el peronismo derrotado mantuvo un perfil bajo. En Neuquén se pudo constatar acciones de ocultamiento de libros, fotos, folletos y la desaparición del busto de Eva Perón en San Martin de los Andes. Pero la agitación obrera se manifestó como una forma de resistencia civil. En esta provincia las autoridades militares y vecinos manifestaron la preocupación por el personal obrero en la Comisión de Energía Atómica de Loncopue en estado de rebelión, disponiéndose la separación de varios empleados y la exhoneración del secretario del gremio. También se registraron incidentes en los sindicatos petroleros de ASTRA e YPF en Chubut, en los que el antiperonismo había retomado el control y en la ciudad de Caleta Olivia, en la que fue allanada la casa del suboficial del Ejercito, peronista y dirigente de la Alianza Libertadora Nacionalista Federico Troxler, involucrado en el conflicto en las petroleras chubutenses. ${ }^{55}$

En cuanto a los resultados, en Río Negro hubo aproximadamente 400 denuncias sobre asociaciones e instituciones y 60 denuncias contra particulares. La Comisión Provincial elevó 35 sumarios a la justicia y 45 casos quedaron abiertos para continuar las investigaciones. En la Provincia Patagonia la Comisión Provincial al finalizar su tarea elevo al gobierno nacional 73 causas, de las que finalizaron 33, se pasaron a la Justicia 13 y se dejaron abierta para nuevas investigaciones 27.56 En Chubut el Informe de la Comisión declaró que no se habían realizado detenciones ni procedimientos policiales. ${ }^{57}$

\section{Conclusiones}

Con el golpe militar de 1955, Argentina transitó un camino tortuoso en el que la exclusión política de amplios sectores de la población fue la nota dominante. La decisión de proscribir y desperonizar profundizó la polarización ya advertible en los años finales del peronismo y la condensó en la necesidad imperiosa de investigar, difundir los resultados y castigar a los culpables de delitos públicos durante la administración peronista.

La argumentación utilizada para justificar el golpe y la represión posterior demuestra la manipulación de conceptos claves de nuestro sistema político como democracia, constitución, participación en función de los intereses golpistas, con

\footnotetext{
54 AGN-FNRP, Comisiones Provinciales, Caja 1, Patagonia, Expediente 51025/56, Memoria Incompleta de la Comisión Provincial de Investigaciones, f 6.

${ }^{55}$ AGN-FNRP, Comisiones Provinciales, Caja 1,Neuquén, Expediente No 102.568, 17/4/1956; AGNESCR, Caja 133, Expediente 149, 1956 ; AHCH, Rollo 1228,Expediente 3014-R, 19/10/1955; Rollo 1234, Expediente 4425-I, $1^{\circ}$ /12/1955; ASC-PP, Legajo 4, Expediente 9174, octubre de 1955, entre otros.

56AGN-FNRP, Caja 1, Patagonia, Expediente 51025/56, Memoria Incompleta de la Comisión Provincial de Investigación.

57 República Argentina. Vicepresidencia de la Nación, Comisión Nacional de Investigaciones. Documentación, autores y cómplices de las irregularidades cometidas durante la segunda tiranía, Tomo IV, Buenos Aires, 1958, pp. 451-452.
} 


\section{Martha Ruffini}

expresiones que aluden a la actuación militar como parte de la responsabilidad histórica asumida, último y necesario eslabón para la reparación y corrección del rumbo de la argentinidad. Al utilizar metáforas organicistas para explicar la profundidad de la represión, tensan la misma hasta los extremos como una invitación a actuar sin hesitar. Con esta orientación, el clímax de la violencia fue en aumento. Investigaciones, persecuciones, detenciones, arrestos y fusilamientos formaron parte del escenario político y constituyeron una modalidad de dominación que si bien generó resistencia civil, fue naturalizada por la mayoría de la población como parte de la tendencia democrática inspirada por los radicales golpistas.

Las nuevas provincias del sur iniciaban su administración autonómica en un contexto signado por una conducción nacional dictatorial con la violencia como parte de la cotidianeidad del poder. La colaboración de la sociedad civil le otorgó un manto de legitimidad a las acciones represivas que en la Patagonia estuvieron encabezadas por los interventores militares auxiliados por la policía y con la colaboración de las Comisiones Investigadoras provinciales y sub comisiones que sugirieron medidas, opinaron y dictaminaron en numerosas causas. Los destinatarios eran aquellos que podian incidir sobre la población ya sea dictando procederes o difundiendo valores contrarrevolucionarios. El personal de las escuelas -directores y maestras- estuvieron en el centro de la atención por su capacidad de influir pero tambien por el lugar prominente que ocupaban en la sociedad provincial, conjuntamente con los jueces de paz y en menor medida, directores de hospitales y gremialistas.

Este rasgo fundacional evidentemente incidió en los formatos politicos de las provincias y en la adhesión a los principios revolucionarios de políticos, medios de prensa y corporaciones claramente observables en los debates de los convencionales constituyentes en 1957 y en la presencia permanente de los principios de la Revolución Libertadora en los discursos de la dirigencia política patagónica hasta 1966.

Llama la atención que las provincias del sur no cuestionaran la exclusión. Politicamente no habían participado de las instancias de decision politica nacional desde la creación de los territorios en 1884. Podríamos pensar que esta marginalidad vivida y sufrida -que hemos llamado legado territorial- debería haber operado como un atenuante de la exclusión. Sin embargo, el involucramiento de las fuerzas politicas actuantes en la etapa territorial en las instituciones revolucionarias y el compromiso de gran parte de la sociedad civil como respuesta al llamado a denunciar e informar, desmienten esta a presunción o al menos le otorgan matices. Creemos que la tendencia que se desplegó e impuso con mayor fuerza fue la del antiperonismo latente en los sectores dominantes territoriales, desplazados del poder en forma completa entre 1946-1955, y que creían que sostener la proscripción les aseguraría el mantenimiento del poder político por largo tiempo. La debilidad en la concepción de la democracia como sistema político incluyente y participativo tuvo en las provincias del sur un primer signo distintivo motivador de 


\section{Tiempos antiperonistas en la Patagonia argentina}

conflictos entre poderes del Estado y desplazamientos de gobernadores constitucionales durante la década de 1960.

\section{Fuentes Primarias}

Anales de Jurisprudencia Argentina ,Tomo XVI-A, Decretos, 1956.

Archivo General de la Nación, Archivo Intermedio, Fiscalía Nacional de Recuperación Patrimonial, Clasificación y custodia de actuaciones. Comisiones Provinciales Neuquén,Patagonia,Río Negro y Chubut.

Archivo General de la Nación, Departamento Archivo Intermedio, Fiscalía Nacional de Recuperación Patrimonial, Comisión Nacional de Investigaciones. Memoria de las Comisiones Provinciales. Cajas 12 y 13.

Archivo General de la Nación. Archivo Intermedio. Comisión de Ordenamiento de Archivos. Expedientes Secretos, Confidenciales y Reservados.

Archivo Histórico de Chubut. Fondo Documental Gobernación del territorio del Chubut, 1885-1957, Expedientes Microfilmados, Rollos № 1224 a 1258.

Archivo Histórico de la provincia de Río Negro, Sección Administración de Gobierno. Expedientes Generales. 1955-1956.

Archivo Histórico de la provincia de Santa Cruz. Fondo Gobernación de la provincia. Sección Provincia Patagonia, 1955-1956.

Presidencia de la Nación. Memoria del gobierno Provisional de la Revolución Libertadora. 1955-1958. Buenos Aires, 1959.

República Argentina. Libro Negro de la segunda tiranía. Decreto-ley $\mathrm{n}^{\circ}$ 14988/56.Buenos Aires, 1958.

Vicepresidencia de la Nación, Comisión Nacional de Investigaciones. Documentación, autores y cómplices de las irregularidades cometidas durante la segunda tiranía, Tomo IV, Buenos Aires, 1958.

\section{Bibliografía}

Aixa Bona y Juan Vilaboa, (Coordinadores). Las formas de la política en la Patagonia. Buenos Aires, Biblos, 2007.

Aixa Bona y Juan Vilaboa. "La transición política de los territorios nacionales y la caída del peronismo. El caso de Santa Cruz", ponencia presentada en III Jornadas de Historia de la Patagonia, San Carlos de Bariloche, Río Negro, 2008.

Silvana Ferreyra. "El delito de ser peronista.Una aproximación a las Comisiones Investigadoras durante la Revolución Libertadora", ponencia presentada en IV Congreso de Estudios sobre Peronismo, San Miguel de Tucumán, Tucumán, 2014.

Antonio Gramsci. Notas sobre Maquiavelo, sobre la política y el Estado moderno.Buenos Aires, Nueva Visión, 1987.

Graciela Iuorno. "La provincialización de Río Negro, Interregno y conflicto de intereses nacionales y locales", en Martha Ruffini y Ricardo Freddy Masera, 


\section{Martha Ruffini}

(Coordinadores), Horizontes en perspectiva. Contribuciones para la historia de Río Negro 1884-1955. Viedma, Legislatura de Río Negro, 2007.

Daniel James. Resistencia e integración. El peronismo y la clase trabajadora argentina. Buenos Aires, Siglo XXI editores, 2003.

Enrique Mases y Mariano López Cuminao. "La luz de un fósforo fue. Auge y decadencia de la Unión Cívica Radical Intransigente Neuquina 1957-1962", en Francisco Camino Vela, (Compilador), El mundo de la política en la Patagonia Norte.Neuquén, Editorial de la Universidad del Comahue EDUCO, 2012.

Guillermo O'Donnell y Philippe Schmitter. Transiciones desde un gobierno autoritario. Buenos Aires, Prometeo, 2010.

Gabriel Rafart y Enrique Mases. El peronismo desde los territorios a la Nación. Su historia en Neuquén y Río Negro 1943-1958. Neuquén, Editorial de la Universidad del Comahue EDUCO, 2001.

Martha Ruffini. "La Revolución Libertadora en el sur argentino. Persecución política y antiperonismo en río Negro”. Revista e@latina, Vol.XI, N41. Buenos Aires, 2012, pp. 37-58.

María Sáenz Quesada. La Libertadora. Historia pública y secreta.1955-1958. Buenos Aires, Sudamericana, 2007.

Catalina Scoufalos. 1955. Memoria y resistencia. Buenos Aires, Biblos, 2007.

María Estela Spinelli. Los vencedores vencidos. El antiperonismo y la revolución libertadora. Buenos Aires, Biblos, 2005.

Recibido: $14 / 02 / 2016$

Evaluado: 20/03/2016

Versión Final: 19/04/2016 